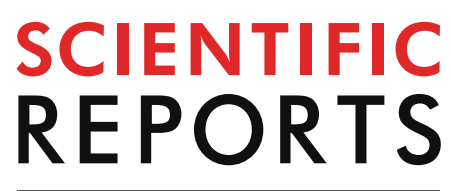

natureresearch

Check for updates

\title{
OPEN The rapid CD4 + T-lymphocyte decline and human immunodeficiency virus progression in females compared to males
}

\author{
Nader Parsa ${ }^{1}$, Pari Mahlagha Zaheri ${ }^{2}$, Ross G. Hewitt ${ }^{3}$, Ali Karimi Akhormeh $\mathbb{1}^{1}$, \\ Samira Taravatmanesh ${ }^{2} \&$ Lisa Wallin ${ }^{4 凶}$
}

CD4 + T-lymphocyte counts are used to assess CD4 + decline and the stage of human immunodeficiency virus (HIV) progression in HIV-infected patients. Clinical observation suggests that HIV progress more rapid in females than males. Of the original $5000 \mathrm{HIV}$-infected population of Western New York HIV/ AIDS, Referral Center at Erie County Medical Center (ECMC), 1422 participated in the cohort study. We identified $333 \mathrm{HIV}$-infected patients with CD4 + T-cell-counts $\geq 500 / \mu \mathrm{l}$, among them 178 met the inclusion criteria for the 10 -year study. Females had higher mode ( 600 vs. 540 ) and mean (741.9 vs. 712.2) $\mathrm{CD} 4$ + counts than males at baseline. However, $\mathrm{CD} 4+$ declined faster among females in a shorter time than males $(234.5$ vs. $158.6, P<0.004)$, with rapid HIV progression. Univariate analyses determined that females had a $40 \%$ higher risk for $\mathrm{CD} 4+$ decline than males. The bivariate analyses specified CD4 + decline remained greater in females than males. Multivariate analyses which employed Cox's proportional Hazard-Model to adjust for numerous variables simultaneously identified women had almost twice the risk for $\mathrm{CD} 4$ + decline and rapid HIV progression than males $(R R=1.93 ; 95 \% \mathrm{Cl}$ $1.24,2.99)$. Although the biological mechanism remains unknown, findings suggest gender differences in CD4 + decline, with a higher risk of rapid HIV progression and shorter longevity in females.

HIV is a contagious, deadly disease that has rapidly spread worldwide ${ }^{1}$. It is a member of the lentivirus group of retroviruses that specifically infects T-lymphocyte white blood cells (WBC) with CD4+ surface receptors ${ }^{2}$. The HIV virus then attacks CD4 + T-cells, kills them, decreases immune function, and leads to opportunistic infections (OI's) and rare cancers. It is very rare for OI's to occur when the CD4+T-lymphocyte count is $\geq 500 \mu l^{3}$. Within a week or two of infection, p24 antigen appears in the blood, followed in about 6-10 weeks by p24 antibodies.

Normally replication of HIV virus is greater than several hundred million per day ${ }^{4}$. The strongest implication associated for HIV progression is the depletion of CD4 + T-lymphocytes in the immune system ${ }^{3}$. The half-life of the virus is two days, with approximately $30 \%$ of virus replication occurring in 24 -h, and complete turnover of the entire virus population every 14 days $^{5}$. The rate of CD $4+$ T-lymphocyte decline can vary but averages $40-80 \mathrm{cells} / \mu \mathrm{l} /$ year $^{6}$.

The 2019 Centers for Disease Control (CDC) and Prevention reported females in 2016 were more than $20 \%$ of HIV-infected persons in the United States ${ }^{7}$. The World health organization (WHO) and the United Nations Program on AIDS (UNAIDS) identified nearly 50\% (18.8 million) of HIV-infected patients worldwide are females ${ }^{8}$.

The significant gender differences such as gender-based beliefs, unfavorable cultural diversity, violence, lack of accessing care and so on, make women in particular more vulnerable to becoming HIV-infected in ways that correspond to their risk perception ${ }^{9,10}$. Due to socio-demographic and socio-behavioral status, females appeared to be more susceptible to increase risk of CD4 + decline and HIV progression compared with males ${ }^{11}$.

${ }^{1}$ Cardiovascular Research Center, Shiraz University of Medical Sciences, Shiraz, Iran. ${ }^{2}$ Shiraz University of Medical Sciences, Shiraz, Iran. ${ }^{3}$ University at Buffalo, State University of New York, Buffalo, NY, USA. ${ }^{4}$ Strong Memorial Hospital, University of Rochester, Rochester, NY, USA. ${ }^{\circledR}$ email: drnaderparsabe930@gmail.com 


\begin{tabular}{|c|c|c|c|}
\hline CD4 + T-Cell & A1 & B1 & C1 \\
\hline CD4 + T-lymphocyte counts $\geq 500 / \mu \mathrm{l}$ & $\begin{array}{l}\text { Asymptomatic HIV-infection, Acute primary } \\
\text { HIV-infection with illness or history of acute HIV- } \\
\text { infection or PGL* }\end{array}$ & $\begin{array}{l}\text { Symptomatic conditions but not with acute HIV- } \\
\text { infection, PGL or any HIV indicator conditions }\end{array}$ & With AIDS indicator conditions \\
\hline
\end{tabular}

Table 1. CDC stages definition. ${ }^{\star} P G L$ persistent generalized lymphadenopathy.

Previous studies identified that females had a higher CD4 + T-cell count ${ }^{12-18}$ at the beginning of infection compared to males. In other studies, gender differences showed rapid CD4 + decline and HIV progression in females compared to males ${ }^{12,14,19-21}$. Therefore, for any given CD4 + T-cell count, females may be at a higher risk of HIV progression and female gender by itself, appears to increase risk of HIV progression compared to males. Consequently, the aim of this study was to examine the possible gender difference in CD4 + T-lymphocyte decline and HIV progression.

\section{Material and methods}

Design. This is a longitudinal cohort study conducted on HIV-infected patients that excluded patients with the following criteria: 1) If they were placed on any type of combination antiretroviral medication or protease inhibitors (PI's) that may interfere with the natural history of progression, 2) CD4 + T-lymphocyte count $<500 /$ $\mu l, 3)$ pregnant woman at entry or within the first 6 months of the study, 4) diagnosed with non-HIV-immunosuppression, 5) patients with signs/symptoms of OI's, and 6) who die within the first 6 months of the study. However, inclusion criteria were HIV-infected subject with CD4+ T-lymphocyte counts $\geq 500 / \mu l$ without above exclusion criteria.

Study population. The target population was 5000 HIV/AIDS-infected subjects served through initial visits and continuing care revisits from diverse socioeconomic, ethnic, and racial groups, by the immunodeficiency department, who attended the WNY HIV/AIDS Referral Center at ECMC over a 10-year period.

Ethical considerations. This study was in accordance with the Health Sciences Institutional Review Board (HSIRB) of the State University of New York, Buffalo Institutional Review Board (SUNYBIRB) Permissions and had been approved at the WNY HIV/AIDS Referral Center at ECMC, related to any unanticipated problems involving risk to human subject and any serious adverse events before data collection.

Sample size. Of the original population 1,422 participants (1,111 males, $311 \mathrm{females}), 333 \mathrm{HIV}$-infected patients were identified with a CD $4+$ T-cell count $\geq 500 / \mu \mathrm{l}$ (231 males, 102 females). After deletion of patients who met specific exclusion criteria, $178 \mathrm{HIV}$-infected subjects with CD4 + T-lymphocyte counts $\geq 500 / \mu \mathrm{l}$ corresponding to CDC stage- $\boldsymbol{A} \mathbf{1}$ definition as followed remained for the 10 -year study evaluation in Table $1^{22}$.

Most patients were diagnosed with HIV initially at the ECMC private practice clinics, the Women's Clinic, and at the Immunodeficiency Department. Less than 5\% of study patients who were referred from other facilities were followed by this department.

In this study gender as the independent variable was assessed by medical record review of cases during the study period. Study participants were divided by gender for analyses. The outcome variable was CD4 + T-lymphocyte decline as a precursor to HIV progression according to International Classification of Disease, 10th revision (ICD-10) ${ }^{23}$.

The ECMC Immunodeficiency Department is a major referral center in WNY for HIV detection and treatment with well-trained staff and advanced clinical diagnostic laboratory were used for study. Diagnosis of eligible HIV-infected subjects was ascertained by sero-immunologic techniques, such as EIA ${ }^{24,25}$, ELISA and confirmed by Western Blot ${ }^{25-27}$, to detect HIV antibodies. The CD4 + T-cell counts were confirmed by flow-cytometry technique in the tertiary level (level-3) certified laboratory of ECMC and recorded in the medical file. Eligible HIV-patients were followed for at least 6 months within the study period. Pregnant patients were included in the study if the pregnancy occurred after the first 6 months of investigation.

Covariates. Several covariates such as a) clinical; b) hematology (Complete blood cell count (CBC)/ Differential automated (Diff.); c) socio-demographic (supplemental Tables 1,2) and; d) socio-behavioral risk factors (supplemental Tables 3,4) were used to control for possible confounding or interaction.

Statistical analyses. According to the sample size, normality of data was checked by using ShapiroWilk-test. Also, using independent $\boldsymbol{t}$-test to compare between continuous variables and using chi-square-test to compare categorical data. Continuous variables were expressed as mean $\pm \mathrm{SD}$ and categorical variables were expressed as percent (number).

Statistical analyses used descriptive and survival analyses (such as, Kaplan-Meier, Cox's proportional hazard models for univariate, bivariate and multivariate). Kaplan-Meier for plotting trends of CD4 + T-lymphocyte decline and HIV progression associations by gender. Univariate, Bivariate and Multivariate Cox's proportional hazard model were used to adjust for a number of covariates simultaneously to estimate the hazard ratio (HR) of CD4 + T-cell decline and HIV progression by gender and, taking into account the time between the initial CD4 + base value and the latest immunologic status (endpoint CD4 + T-lymphocyte $<500 / \mu l$ ). Data analysis is accomplished by utilizing the advanced version of SPSS. 


\begin{tabular}{|c|c|c|c|c|c|c|c|}
\hline \multirow[b]{3}{*}{ Variable } & \multicolumn{2}{|l|}{ Gender } & \multirow{2}{*}{\multicolumn{5}{|c|}{ Statistical analysis }} \\
\hline & \multirow{2}{*}{\begin{tabular}{|l|} 
Male $(\mathrm{n}=118)$ \\
Mean \pm SD
\end{tabular}} & \multirow{2}{*}{\begin{tabular}{|l|} 
Female $(n=60)$ \\
Mean \pm SD \\
\end{tabular}} & & & & & \\
\hline & & & Mean Diff & SE Diff & 95\%confidence interval & $t$-test & Sig (2-tailed) \\
\hline CD4 base value $(\mu \mathrm{l})$ & $712.2 \pm 186.6$ & $741.9 \pm 301.5$ & -29.6 & 36.72 & $(-102.11,42.84)$ & -0.807 & 0.421 \\
\hline $\begin{array}{l}\text { Length of time (months) from initial HIV + diagnosis to First } \\
\text { CD4 count }\end{array}$ & $7.20 \pm 16.31$ & $7.45 \pm 15.17$ & -0.2805 & 2.528 & $(-5.27,4.71)$ & -0.1 & 0.912 \\
\hline Follow-up length (months) & $25.5 \pm 17.4$ & $21.9 \pm 16.9$ & 3.58 & 2.74 & $(-1.83,8.98)$ & 1.318 & 0.193 \\
\hline CD4 decline $(\mu \mathrm{l})$ during the follow-up time & $158.6 \pm 120.3$ & $234.5 \pm 204.6$ & -75.9 & 26.32 & $(-127.93,-23.93)$ & -2.89 & 0.004 \\
\hline
\end{tabular}

Table 2. Test Results with Equal Variances for CD4 Base Value, Length of Follow-up, and CD4 Decline during the Follow-up Time for HIV-Infected Males $(n=118)$ Compared with HIV-Infected Females ( $n=60)$. Diff, Difference; Sig, Significance.

\begin{tabular}{|c|c|c|c|c|c|c|}
\hline \multicolumn{2}{|l|}{ Variable } & \multirow{2}{*}{\begin{tabular}{|l|} 
Male \% $(\mathbf{n}=118)$ \\
$75.4(89)$
\end{tabular}} & \multirow{2}{*}{\begin{tabular}{|l|} 
Female $\%(\mathbf{n}=\mathbf{6 0})$ \\
$58.3(35)$
\end{tabular}} & \multirow{2}{*}{$\begin{array}{l}\text { Total } \%(\mathbf{n}=\mathbf{1 7 8}) \\
70.0(124)\end{array}$} & \multirow{3}{*}{$\begin{array}{l}\chi^{2} \\
6.0\end{array}$} & \multirow{3}{*}{$\begin{array}{l}p \text { value } \\
0.02\end{array}$} \\
\hline \multirow{3}{*}{ CD4 Decline Status: } & $\begin{array}{l}\text { Non-rapid } \\
\text { progressor(CD4decline }<200 / \mu l)\end{array}$ & & & & & \\
\hline & $\begin{array}{l}\text { Rapid Progressor }(\mathrm{CD} 4 \\
\text { decline }>200 / \mu \mathrm{l})\end{array}$ & $24.6(29)$ & $41.7(25)$ & $30.0(54)$ & & \\
\hline & Total & $100.0(118)$ & $100.0(60)$ & $100.0(178)$ & & \\
\hline
\end{tabular}

Table 3. Compared non-rapid progressor and rapid progressor of CD4 decline status during the follow-up time for HIV-infected males and females.

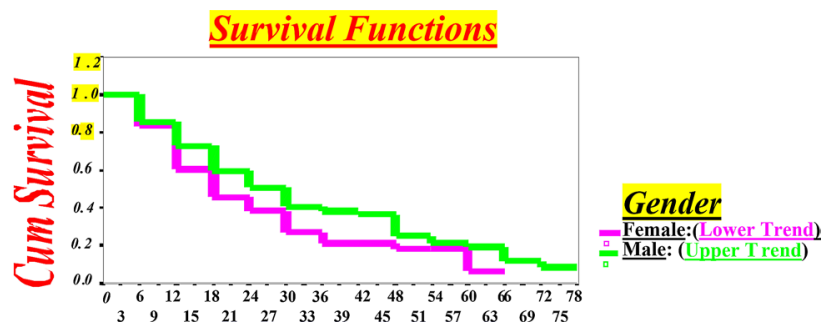

Figure 1. CD $4+$ Decline by Months for Western New York HIV-infected Subjects up to Endpoint $(<500 / \mu \mathrm{L})$ in HIV-infected Females compared to Males by Survival Functions Model.

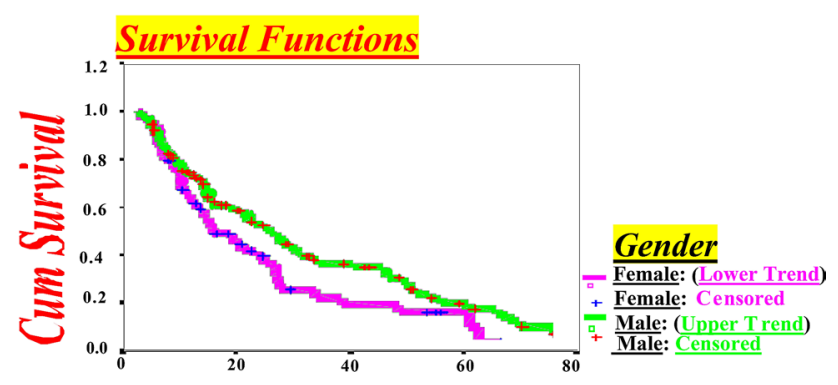

Figure 2. CD4 + Decline by Months for Western New York HIV-infected Subjects up to Endpoint $(<500 / \mu \mathrm{L})$ in HIV-infected Females compared to Males by Survival Functions Model.

Informed consent. Informed consent was obtained from each participant.

\section{Results}

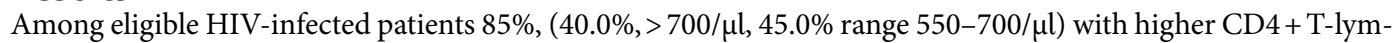
phocyte counts and only $15 \%$, range $500-549 / \mu \mathrm{l}$ ) were identified for the study.

Table 2 shows females mean CD 4 + base value is greater than males $(741.9$ vs.712.2, $P=0.421)$. The mean of the length of time from initial HIV positive diagnosis to the first CD4 + T-lymphocyte count, is similar in both 


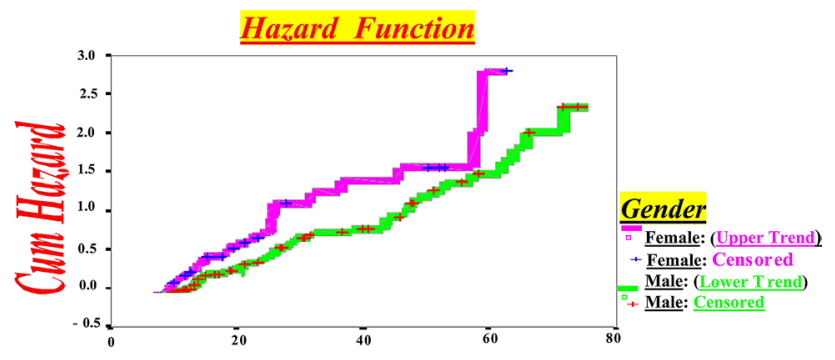

Figure 3. CD $4+$ Decline by Months for Western New York HIV-infected Subjects up to Endpoint $(<500 / \mu L)$ in HIV-infected Females compared to Males by Hazard Function Model lower women's longevity.

\begin{tabular}{|c|c|c|c|c|c|c|c|}
\hline \multirow[b]{3}{*}{ Variable } & \multicolumn{2}{|l|}{ Gender } & \multirow{2}{*}{\multicolumn{5}{|c|}{ Statistical analysis }} \\
\hline & \multirow{2}{*}{$\begin{array}{l}\text { Male }(\mathrm{n}=118) \\
\text { Mean } \pm \text { SD }\end{array}$} & \multirow{2}{*}{$\begin{array}{l}\text { Female }(n=60) \\
\text { Mean } \pm \text { SD }\end{array}$} & & & & & \\
\hline & & & Mean Diff & SE Diff & $\begin{array}{l}\text { 95\% Confidence } \\
\text { Interval }\end{array}$ & t-Test & Sig. (2-tailed) \\
\hline $\begin{array}{l}\text { White Blood Cell (WBC) } \\
\text { k/cumm }\end{array}$ & $6.7 \pm 1.8$ & $6.1 \pm 1.8$ & 0.541 & 0.285 & $(-0.02,1.10)$ & 1.899 & 0.059 \\
\hline Lymphocyte Percent & $36.9 \pm 11.9$ & $35.9 \pm 12.2$ & 0.999 & 1.895 & $(-2.74,4.74)$ & 0.527 & 0.599 \\
\hline Platelet k/cumm & $251.0 \pm 69.0$ & $280.0 \pm 75.0$ & -29.33 & 11.142 & $(-51.32,-7.34)$ & -2.63 & 0.001 \\
\hline
\end{tabular}

Table 4. Test results with equal variances for laboratory-haematology: white blood cell (k/cumm), lymphocyte percent and platelet $(\mathrm{k} / \mathrm{cumm})$, results for HIV-infected males $(\mathrm{n}=118)$ compared with HIV-infected females $(\mathrm{n}=60)$. Diff., Difference; Sig., Significant.

\begin{tabular}{|c|c|c|c|c|c|c|c|c|c|c|c|}
\hline \multirow[b]{2}{*}{ Analysis } & \multirow[b]{2}{*}{ Models } & \multirow[b]{2}{*}{ Variable } & \multicolumn{9}{|c|}{ Statistical Analysis } \\
\hline & & & $\mathbf{n}$ & Events \% (n) & Censored \% (n) & $\beta$ (Beta) & $\operatorname{SE}(\beta)$ & {$[\beta / \mathrm{SE}(\beta)]^{2}$} & Sig. (P-Value) & HR (eß) & $95 \%$ CI for $\mathrm{e} \beta$ \\
\hline \multirow{4}{*}{ Univariate } & \multirow{3}{*}{ Model-1 } & Gender: & 178 & $67(119)$ & \multicolumn{6}{|l|}{$33(59)$} & \\
\hline & & 1. Males & 118 & & & 0 & 1 & Referent & 0 & 1 & Referent \\
\hline & & 2. Females & 60 & & & 0.343 & 0.194 & 3.114 & 0.0700 & 1.4 & $0.96,2.06$ \\
\hline & Model-2 & $\begin{array}{l}\text { CD4+T-Cell } \\
\text { Base Value (in } \\
\text { Hundreds) }\end{array}$ & 178 & $67(119)$ & $33(59)$ & -0.255 & 0.066 & 14.674 & 0.0001 & 0.9 & $0.68,0.88$ \\
\hline \multirow{4}{*}{ Bivariate } & \multirow{4}{*}{ Model-1 } & Gender: & 178 & $67(119)$ & \multicolumn{7}{|l|}{$33(59)$} \\
\hline & & 1. Males & 118 & & & 0 & 1 & Referent & 0 & 1 & Referent \\
\hline & & 2. Females & 60 & & & 0.352 & 0.194 & 3.279 & 0.0701 & 1.4 & $0.97,2.08$ \\
\hline & & $\begin{array}{l}\text { CD4+T-cell } \\
\text { base value (in } \\
\text { hundreds) }\end{array}$ & 178 & $67(119)$ & $33(59)$ & -0.251 & 0.066 & 14.319 & 0.0002 & 0.8 & $0.68,0.88$ \\
\hline \multirow{5}{*}{ Multivariate } & \multirow{5}{*}{ Model-1 } & Gender: & 178 & $69(119)$ & \multicolumn{7}{|l|}{$33(59)$} \\
\hline & & 1. Males & 118 & & & 0 & 1 & Referent & 0 & 1 & Referent \\
\hline & & 2. Females & 60 & & & 0.657 & 0.223 & 8.628 & 0.0033 & 1.93 & $1.24,2.99$ \\
\hline & & $\begin{array}{l}\text { CD4 + T-Cell } \\
\text { Base Value (in } \\
\text { Hundreds) } \\
\end{array}$ & 178 & 67 (119) & $33(59)$ & -0.387 & 0.093 & 17.313 & 0.0001 & 0.7 & $0.56,0.81$ \\
\hline & & $\begin{array}{l}\text { Gender \& } \\
\text { CD4+T-Cell } \\
\text { base value (in } \\
\text { Hundreds) and } \\
\text { other covariates } \\
\text { in study }\end{array}$ & 178 & 67 (119) & $33(59)$ & 0.281 & 0.117 & 5.779 & 0.0162 & 1.3 & $1.05,1.66$ \\
\hline
\end{tabular}

Table 5. Univariate, bivariate results of female gender and started CD4 + T-Cell base value modeling and multivariate modeling and CD4 + T-Cell Base value simultaneously with other possible important covariates associated with CD4 + decline toward to HIV progression during study period. Sig., Significant; e $\beta$, Hazard Ratio (HR); CI, Confidence Interval. Other Covariates* ${ }^{\star}$ clinical, hematology (Complete blood cell count (CBC)/Differential automated (Diff.), socio-demographic (supplemental Tables 1, 2) and socio-behavioral risk factors (supplemental Tables 3, 4) were used to control for possible confounding or interaction. 
genders (7.45 vs. 7.20). However, females mean length of follow-up time for CD4 + decline is shorter than males (21.9 vs. 25.5), as they had a more rapid CD4 + T-cell decline. Mean CD4 + T-lymphocyte decline is approximately 1.5 times greater in females than males (234.5 vs. 158.6). Despite higher CD $4+$ base values and shorter followup times for females compared to males this difference was significant, (95\% CI: $-127.93,-23.93, P=\mathbf{0 . 0 0 4})$.

In Table 3 results identified significantly that HIV-infected females progressed more rapidly than males (41.7\% vs. $24.6 \%, P<0.02)$.

Survival analysis results were laid out by specific aims and sub-hypotheses content. Before we began to analyze numeric results, we observed survival curves that displayed the trend of gender differences and CD4 + T-lymphocyte decline by Kaplan-Meier plots and Hazard Function Models.

This allowed for better examination of functions and comparison of gender role in CD4+ T-lymphocyte decline in a clear way, which leads us to assess rapid HIV progression more accurately in females compared to males. In fact, Kaplan-Meier plots identified females CD4 + T-lymphocyte decline is more rapid and leads to HIV progression compared to males. This indicates the longer the trend, the larger the differences of survival and vice versa (Figs. 1, 2).

Furthermore, Hazard model identified women's longevity is shorter than men (Fig. 3).

Table 4 shows the initial hematology-laboratory results. Initial WBC results identified no significant differences between females and males $(95 \% \mathrm{CI}:-0.02,1.10, P=0.059)$. Lymphocyte percent identified no significant results for females and males $(95 \% \mathrm{CI}:-2.74,4.74, P=0.599)$. However, platelets were significantly higher for females compared to males (95\% CI: $-51.32,-7.34, P=0.001)$, but fell into normal reference ranges $\left(150-450 \times 10^{3} /\right.$ $\mu \mathrm{l})$ and these differences lead to a more rapid progression of HIV in females.

Moreover, numerous factors such as socio-demographic, socio-behavioral, clinical manifestations, biological, environmental, laboratory and frequency of infectious diseases presentation that may affect the natural history of HIV progression between or within genders as covariates simultaneously in univariate, bivariate and multivariate modeling were assessed by Cox's proportional-hazard models. Consequently, models in Table 5 shows female gender increased the risk of CD4 + T-Lymphocyte decline than male.

In this study clinical observation suggests that HIV progression in females is more rapid compared to males. Univariate analysis identified that female gender increases the risk of CD4 + decline by $40 \%(\mathrm{HR}=1.4 ; 95 \% \mathrm{CI}$ 0.96, 2.06). The relation between CD4 + T-Lymphocyte "as a component of the WBC" base value (in hundreds) and HIV progression reached significant $(\mathrm{HR}=0.9 ; 95 \% \mathrm{CI} 0.68,0.88)$. On the other hand, the significance hazard ratio and confidence interval calculations for one-unit change for CD 4 + base value $(\mathrm{HR}=0.9 ; 95 \% \mathrm{CI} 0.88$, $0.99)$ are close to one.

In terms of bivariate analysis, we examined risk factors which may play a role in observed differences in HIV progression associated with gender. As anticipated, bivariate analysis was similar to univariate analysis, identified hazard ratio was not remarkably changed when gender was examined with the other single covariate separate models $(\mathrm{HR}=1.4$; 95\%CI 0.97, 2.08).

Building the best model and getting similar answers for the variables of interest, related to the main hypotheses, determines the multivariate model that fits the data. Therefore, before applying multivariate analysis it is necessary to confirm the following clarifications. Utilizing the Wald-Forward-Stepwise analysis, there was no change in regression coefficients and no major change in relation to gender and CD $4+$ decline, by adding more variables to the model. Adding other variables and getting a similar answer for female gender and CD4+ decline, signifies the stability of the model and the best fit.

Consequently, the relationship between covariates and the outcome variable, as indicated in this model, are remarkably consistent with separate models of univariate and bivariate and quite reasonably stable condition for female gender and rapid CD4 + decline. At the same time, we test for interaction of gender and other covariates in the model, and "no interaction" was noted. However, few suspicious variables and discrepancy in HR estimated were not seen for univariate, bivariate, and interaction analyses. For real interaction we performed stratified analysis to detect the actual effect of these variables. However, there were no existing effects.

Hence, by considering all the variables, analysing them in various ways and steps to approve different routes and ending up with a similar answer for our main hypotheses, we are assured that multivariate Cox's proportional-hazard models are the best fit in our analyses.

The result of multivariate modeling, after including all covariates assessments significantly identified that female gender increases the HR of HIV progression by two-fold (HR=1.93; 95\% CI:1.24, 2.99).

\section{Discussion}

In this study, we hypothesized that CD4 + T-lymphocyte decline during follow-up time leads to HIV progression more rapidly in females than in males.

In this study, a significantly higher proportion of HIV-infected females (41.7\%) were rapid progressor than males $(24.6 \%)$ over a shorter follow-up period $(P<0.02)$.

We examined a variety of risk factors which may play a role in observed differences in HIV progression. Thus, after adjusting for different variables in the models in various ways, results did not alter the magnitude of female gender differences in rapid HIV progression. Therefore, a major finding of this study was that females had rapid HIV progression than males despite higher absolute CD4 + T-cell and shorter follow-up time due to more rapid CD4 + decline among females. In study subjects, the mean average CD4 + T-lymphocyte decline in crude analysis for females was approximately 1.5 times higher than males.

Based upon looking at all angles of the variables related to the main question, and having similar results from previous analyses, such as Kaplan-Meier graphical plot, univariate, bivariate, everything fits with our hypotheses. In univariate analysis and bivariate models female gender increased the risk of CD $4+$ T-cell decline by $40 \%$. 
After adjusting gender with all covariates and testing by multivariate Cox's proportional hazard model, we obtain significantly stronger findings with a higher magnitude of 2 -fold hazard ratio for females' rapid CD4 + T-cell decline in shorter follow-up time and HIV progression compared with males over the 10-year period.

For further certainty, overall analyses of this study, from the repeated steps of analyses such as examining for possible potential confounding, interaction and effect modification of other extraneous variables in different models, results indicate the stability of the association of predictor (gender) and outcome variables (HIV progression) in our specific question. These findings are more concrete and consistent with previous studies ${ }^{12,13,19,20,28}$.

One study ${ }^{29}$ identified that women presented with higher absolute CD4 + T-lymphocyte counts than men, however, this difference was not significant. This discrepancy was related to components of their specific question.

Our finding is supported by many other studies and clinician experiences that enumerations of CD4 + T-lymphocytes remain the best immunological steady-state marker of HIV progression and prognosis ${ }^{30-32}$.

For more signifying, since the absolute CD4 + count is calculated based on WBC and lymphocyte percent values, the results of initial WBC and lymphocyte percentage were analyzed. In terms of the magnitude of $\mathrm{CD} 4+\mathrm{T}$-lymphocyte base value, change in one unit apart, results in the hazard ratio and confidence interval close to one. This indicates the issue of the size of the unit for CD4 + T-lymphocyte count, by changing one unit in the risk, is thus based upon one unit apart from the CD4 + T-lymphocyte base covariate. When we change the size of the CD4 + T-lymphocyte base value unit from one to 100 (because CD4 + T-lymphocyte baseline value counts are in the several hundred), the estimate of hazard ratio for CD4 + T-lymphocytes is far below one. Scientifically, this means that the CD4 + T-lymphocyte as a helper cell and immune protection declines more rapidly in females and causes a rapid HIV progression compared to males. Therefore, biological differences between genders have a clear influence on the natural history of HIV disease and the response to therapeutic interventions.

Furthermore, in this study the risk of CD4 + decline and HIV progression in females was approximately twofold higher than in males, and recent results by other researchers ${ }^{12,19,33}$ parallel to this finding, considerations for changes in therapy protocols may need to be made to account for gender differences. Hence, findings of this study may have important clinical applications and epidemiologic significance.

\section{Limitations}

HIV infection data should be interpreted with caution as these data may not be representative of all HIV-infected patients. The number of cases appears to be smaller than expected in the early phases of the study. Therefore, the unequal costs of this type of deficit may not be serious for study subjects due to satisfaction of results. Although the total sample size is not large and females are fewer than males, the obtained results are deemed reliable due to cohort study design and use of appropriate statistical methods to achieve enough power in this study. Increasing the sample size may have a minor impact on the covariate results but not a major impact on the nature of the predictor variable, generalizability, and conclusiveness of the analyses.

Errors from the diagnostic laboratory or clinic (mislabeling of blood specimens, etc.) and systematic errors (test kit, technical or procedural errors, equipment, or contamination of specimens) may lead to limitations and affect the magnitude of hazard ratio. However, due to directed supervision, quality assurance (QA) and quality control (QC) we assume to minimize these potential inaccuracies.

Delayed diagnosis may vary due to patients not seeking medical care and/or "no show" of clinic appointments has minor affects due to the precise measure of HIV progression. Barriers to access to care was postulated to be the reason for the observed gender differences ${ }^{34}$. Therefore, in this study due to thorough management and coordination of the WNY regional area, HIV/AIDS Referral Center at ECMC ensured that all patients received equal access, acceptability, availability, continuity of care, cost-effectiveness, and quality of care.

\section{Strengths}

Study strengths demonstrate possible associations between those risk factors (real or related) and HIV progression by gender.

Minimizing potential biases by frequent QA-QC through all stages of data collection, analyses and cautiously interpreting data related to eligible subjects. Re-evaluation of collected data by the principle investigator in order to re-examine the outcome variable (CD4 + decline) in study subjects, from CD4 + baseline value to study endpoint $(\mathrm{CD} 4<500 / \mu \mathrm{l})$ by employing the absolute count mathematical computation formula used by the ECMC advanced level laboratory ${ }^{35}$. Each CD $4+$ lab test result was re-calculated by the principle investigator for verification of accuracy, validity, reliability of collected data.

Further strength is collected data from diverse geographically normal distributed centers that were providing health care with an abundance of information representative of the targeted WNY HIV-infected cohort population.

Another major benefit in obtaining valid CD4 + T-cell counts, on the study subjects, is that ECMC with advanced lab equipment (e.g. Flow Cytometry device, ...) had the capacity to run all tests without having to send the specimens out for evaluation, that mitigate the risk of inter-laboratory measurement variations and altered results ${ }^{35}$.

\section{Conclusion}

Although the biological mechanism remains unknown, findings suggest there are gender differences in CD4 + decline, with a higher risk of rapid HIV progression and shorter longevity in females. 
Received: 2 October 2019; Accepted: 30 July 2020

Published online: 08 October 2020

\section{References}

1. Dolan, K. et al. Global burden of HIV, viral hepatitis, and tuberculosis in prisoners and detainees. The Lancet 388, 1089-1102 (2016).

2. McLaren, P. J. et al. HIV-exposed seronegative commercial sex workers show a quiescent phenotype in the CD4+ T cell compartment and reduced expression of HIV-dependent host factors. J. Infect. Dis. 202, S339-S344 (2010).

3. Richard, J. et al. Small CD4 mimetics prevent HIV-1 uninfected bystander CD4+ T cell killing mediated by antibody-dependent cell-mediated cytotoxicity. EBioMedicine 3, 122-134 (2016).

4. Katlama, C. et al. Barriers to a cure for HIV: new ways to target and eradicate HIV-1 reservoirs. The Lancet 381, 2109-2117 (2013).

5. Mehla, R. \& Ayyavoo, V. Gene array studies in HIV-1 infection. Current HIV/AIDS Rep. 9, 34-43 (2012).

6. Serrano-Villar, S. et al. HIV-infected individuals with low CD4/CD8 ratio despite effective antiretroviral therapy exhibit altered T cell subsets, heightened CD8+ T cell activation, and increased risk of non-AIDS morbidity and mortality. PLoS Pathogens 10, e1004078 (2014).

7. 7Linley, L. et al. Estimated HIV incidence and prevalence in the United States 2010-2016. (2019).

8. 8Anderson, J. A guide to the clinical care of women with HIV. 2001. Rockville (Md): Department of Health and Human Services, Health Resources and Services Administration, HIV/AIDS Bureau, 242-249 (2005).

9. Anderson, K. G., Beutel, A. M. \& Maughan-Brown, B. HIV risk perceptions and first sexual intercourse among youth in Cape Town. South Africa. Int. Family Plan. Perspect. 33, 98-105 (2007).

10. van den Berg, D. \& Van Rooyen, L. A bird's eye view on the vulnerability of the young girl to HIV infection - a synergy of research. Int. J. Adolesc. Youth 13, 195-219 (2007).

11. Hewitt, R. G., Parsa, N. \& Gugino, L. The role of gender in HIV progression. AIDS Reader N. Y. 11, 29-33 (2001).

12. Prins, M. et al. Do gender differences in CD4 cell counts matter?. AIDS (London, England) 13, 2361-2364 (1999).

13. Braga, P., Cardoso, M.-R.A. \& Segurado, A. C. Gender differences in survival in an HIV/AIDS cohort from Sao Paulo Brazil. AIDS Patient Care and STDs 21, 321-328 (2007).

14. Melnick, S. L. et al. Survival and disease progression according to gender of patients with HIV infection. The Terry Beirn community programs for clinical research on AIDS. Jama 272, 1915-1921 (1994).

15. Maman, D. et al. Gender differences in immune reconstitution: a multicentric cohort analysis in sub-Saharan Africa. PLoS One 7, e31078 (2012).

16. Adal, M., Howe, R., Kassa, D., Aseffa, A. \& Petros, B. Associations of gender and serum total cholesterol with CD4+ T cell count and HIV RNA load in antiretroviral-naïve individuals in Addis Ababa. BMC Public Health 18, 943 (2018).

17. Giles, M. L. et al. Sex-based differences in antiretroviral therapy initiation, switching and treatment interruptions: global overview from the international epidemiologic databases to evaluate AIDS (IeDEA). J. Int. AIDS Soc. 21, e25149 (2018).

18. Takarinda, K. C. et al. Gender-related differences in outcomes and attrition on antiretroviral treatment among an HIV-infected patient cohort in Zimbabwe: 2007-2010. Int. J. Infect. Dis. 30, 98-105 (2015).

19. Motazedian, N., Sayadi, M., Kazerooni, P. A. \& Sabet, M. Gender differences in progression to AIDS and death after HIV diagnosis. Shiraz E-Med. J. 15, 24273 (2015).

20. Martinson, N. A. et al. CD4 and viral load dynamics in antiretroviral-naïve HIV-infected adults from Soweto, South Africa: a prospective cohort. PloS ONE 9, 96369 (2014).

21. Meier, A. et al. Sex differences in the TLR-mediated response of pDCs to HIV-1 are associated with higher immune activation in infected women. Nat. Med. 15, 955 (2009).

22. Vajpayee, M., Kaushik, S., Sreenivas, V., Wig, N. \& Seth, P. CDC staging based on absolute CD4 count and CD4 percentage in an HIV-1-infected Indian population: treatment implications. Clin. Exp. Immunol. 141, 485-490 (2005).

23. 23WHO. International statistical classification of diseases and related health problems. 10th revision., (World Health Organization, Geneva, 2010).

24. Kosack, C. S. et al. Designing HIV testing algorithms based on 2015 WHO guidelines using data from six sites in Sub-Saharan Africa. J. Clin. Microbiol. 55, 3006-3015 (2017).

25. De La Rica, R. \& Stevens, M. M. Plasmonic ELISA for the ultrasensitive detection of disease biomarkers with the naked eye. Nat. Nanotechnol. 7, 821 (2012).

26. Recommendations, C. D. Interpretation and use of the western blot assay for serodiagnosis of human immunodeficiency virus type 1 infections. MMWR Suppl. 38, 1-7 (1989).

27. Parekh, B. S. et al. Diagnosis of human immunodeficiency virus infection. Clin. Microbiol. Rev. https://doi.org/10.1128/cmr.00064 $-18(2019)$

28. Girum, T. et al. Gender disparity in epidemiological trend of HIV/AIDS infection and treatment in Ethiopia. Arch. Public Health 76, 51 (2018).

29. Mosha, F. et al. Gender differences in HIV disease progression and treatment outcomes among HIV patients one year after starting antiretroviral treatment (ART) in Dar es Salaam Tanzania. BMC Public Health 13, 38. https://doi.org/10.1186/1471-2458-13-38 (2013).

30. Turk, G. et al. Biomarkers of progression after HIV acute/early infection: nothing compares to CD4(+) T-cell count?. Viruses https ://doi.org/10.3390/v10010034 (2018)

31. Collaboration, C. Short-term risk of AIDS according to current CD4 cell count and viral load in antiretroviral drug-naive individuals and those treated in the monotherapy era. Aids 18, 51-58 (2004).

32. Goujard, C. et al. CD4 cell count and HIV DNA level are independent predictors of disease progression after primary HIV type 1 infection in untreated patients. Clin. Infect. Dis. 42, 709-715 (2006).

33. Fontdevila, M. C. et al. Plasma HIV-1 tropism and risk of short-term clinical progression to AIDS or death. J. Int. AIDS Soc. 17, 19685. https://doi.org/10.7448/ias.17.4.19685 (2014).

34. Remien, R. H. et al. Gender and care: access to HIV testing, care and treatment. J. Acquir. Immune Defic. Syndr. 51, 106 (2009).

35. Biosciences, B. 50 Tests per kit-Catalog No. 34241450 Tests per kit with BD Trucount ${ }^{\text {tw }}$ Tubes-Catalog No. 342445. (2016).

\section{Author contributions}

Conceptualization: N.P.; Formal analysis: N.P., A.KA.; Methodology: N.P., L.W., R.H. S.T.; Supervision: N.P., L.W., R.H.; Writing—original draft: N.P., A.KA. PM.Z. Writing—review \& editing: N.P., L.W.

\section{Competing interests}

The authors declare no competing interests. 


\section{Additional information}

Supplementary information is available for this paper at https://doi.org/10.1038/s41598-020-73852-0.

Correspondence and requests for materials should be addressed to L.W.

Reprints and permissions information is available at www.nature.com/reprints.

Publisher's note Springer Nature remains neutral with regard to jurisdictional claims in published maps and institutional affiliations.

Open Access This article is licensed under a Creative Commons Attribution 4.0 International License, which permits use, sharing, adaptation, distribution and reproduction in any medium or format, as long as you give appropriate credit to the original author(s) and the source, provide a link to the Creative Commons licence, and indicate if changes were made. The images or other third party material in this article are included in the article's Creative Commons licence, unless indicated otherwise in a credit line to the material. If material is not included in the article's Creative Commons licence and your intended use is not permitted by statutory regulation or exceeds the permitted use, you will need to obtain permission directly from the copyright holder. To view a copy of this licence, visit http://creativecommons.org/licenses/by/4.0/.

(c) The Author(s) 2020 